Proceeding Paper

\title{
Remote Operations Could Be the Future for Earth Sciences Teaching: A Speculative Discussion ${ }^{\dagger}$
}

\author{
Carlos Alves ${ }^{1, *}$, Carlos Figueiredo ${ }^{2}$ and Jorge Sanjurjo-Sánchez ${ }^{3}$ \\ 1 LandS/Lab2PT-Landscapes, Heritage and Territory Laboratory (FCT-UIDB/04509/2020) and Earth Sciences \\ Department/School of Sciences, University of Minho, 4710-057 Braga, Portugal \\ 2 CERENA-Centro de Recursos Naturais e Ambiente, FCT-UIDB/04028/2020, DEcivil, \\ Instituto Superior Técnico, University of Lisbon, 1049-001 Lisbon, Portugal; carlos.m.figueiredo@ist.utl.pt \\ 3 Instituto Universitario de Xeoloxía, Universidad de la Coruña, ESCI, Campus de Elviña, \\ 15071 A Coruña, Spain; jorge.sanjurjo.sanchez@udc.es \\ * Correspondence: casaix@dct.uminho.pt \\ + Presented at the 3rd International Electronic Conference on Geosciences, 7-13 December 2020; \\ Available online: https://iecg2020.sciforum.net/\#.
}

Citation: Alves, C.; Figueiredo, C.; Sanjurjo-Sánchez, J. Remote Operations Could Be the Future for Earth Sciences Teaching: A Speculative Discussion. Environ. Sci. Proc. 2021, 5, 9. https://doi.org/ 10.3390/IECG2020-08736

Academic Editor: Jesus Martinez Frias

Published: 1 December 2020

Publisher's Note: MDPI stays neutral with regard to jurisdictional claims in published maps and institutional affiliations.

Copyright: $\left(C^{2} 2020\right.$ by the authors. Licensee MDPI, Basel, Switzerland. This article is an open access article distributed under the terms and conditions of the Creative Commons Attribution (CC BY) license (http://creativecommons.org/licenses/by/4.0/).

\begin{abstract}
The current COVID-19 pandemic has created havoc in the regular workings of many institutions, such as those dedicated to teaching; therefore, there is an urge for alternatives to traditional face-to-face teaching. However, for certain subjects, such as Earth Sciences, distance-teaching approaches could be seen as counterintuitive to the essential foundations of the subject (where empirical information, especially from fieldwork, is considered paramount for its foundation and growth). In this work, we consider remote operations that could complement, improve, and perhaps even replace the traditional approach for teaching Earth Sciences, potentially producing better learning outcomes, even in relation to laboratory and fieldwork, including studies involving locations outside of planet Earth. Additionally, we consider the possible advantages for other professional settings related to this area, such as those concerning terrain characterization for engineering works, mineral resources, and environmental studies, as well as possible support for space missions and stations in other astronomical bodies (where mineral exploration and extraction could be developed and, hence, benefit from remote operations).
\end{abstract}

Keywords: teaching under isolation conditions; fieldwork; laboratory work; space exploration and exploitation

\section{Introduction}

The current COVID-19 pandemic has caused major disruptions in teaching activities around the world. Given that this is a global issue, it means that there will be a wider, more interested audience (which also means a wider market for remote-based activities in general, including teaching).

One can admit that other generalized isolation situations might happen in the future, possibly due to the occurrence of pandemics (promoted by an increasingly "de facto" borderless world) or to catastrophes promoted by climate change and related events (e.g., floods, landslides).

Moreover, sickness and disability (i.e., of staff or students) can promote general or individual access problems (either temporarily or permanently). The solutions to overcome these situations will have wider social importance (see, for example, [1]).

Besides the immediate questions about teaching, the issues discussed here (concerning the use of remote operations) could be relevant for individuals to develop skills that will be useful in diverse professional settings and possibly help prepare students for 21st- 
century workplaces, where collaborators can participate from anywhere. Just like the internet, which began as a government (military) project, investment in these teaching alternatives could contribute to diverse business opportunities in several geological areas, such as mineral exploration and environmental studies, especially in areas that are not easily accessible, or area with conditional access resulting from, e.g., radioactive conditions.

Teaching based on remote interactions could also have several advantages, in terms of reducing stress, atmospheric pollution, and overcrowding (as a side effect, the reduction of crowding could reduce the number of people exposed to street crime or low-tech terrorist attacks). Remote learning can potentially be more flexible. For example, in terms of scheduling, it will be advantageous for working students, or for people who care for infants, the elderly, or the sick.

\section{Materials and Methods}

The materials included both objects and concepts relevant to Earth Science classes. We attempted to formulate a global discussion that applies to minerals, fossils, rocks, structures, etc. We focused on geological points and did not discuss specific equipment for the execution of remote operations.

We considered two overly broad methodological options: interaction with humans and remotely controlled electronic systems; however, in the analyzed context, interaction with humans will unavoidably involve the use of some kind of electronic system. These are discussed in relation to traditional geological methods (fieldwork, hand sample observation, polarizing microscope, etc.).

We must note a shortcoming of the discussion presented here: we did not consider safety issues related to the considered procedures (which, in some situations, could render them unviable). In general, we also avoided limitations related to economic factors.

\section{Discussion}

Interaction with human agents will be the easiest option to implement in the shortterm, but the least interesting in the long-term, especially considering the possible use of these procedures in future professional settings (namely those in extreme environments, for example, in extraterrestrial places).

A simple and feasible technique for deploying this method (of remote operations by communication with other humans) would be to implement live interactions between teachers and students. This could be presently done without great effort or cost, and there are some examples related to the surveying of distance places (personal communications to the first author from Professor C. Leal Gomes and from Ana Patrícia Matos).

The interactive process can include requests from the teacher for the students to perform specific activities; it can also be performed the other way around - with the students requesting actions from the teacher.

During the current COVID-19 pandemic, a more complex situation is occurring, where some students (but not all) are unable to attend laboratory activities and this might be very pertinent for the future in other situations where some students cannot physically attend the teaching spaces. In this type of situation, it is also necessary to consider the need to preserve the privacy of the students who are present in the teaching spaces.

In these circumstances, at least one human agent will have to leave the usual residence; this option might be problematic if there are extreme circulation restrictions. However, for studies that take place in areas away from human conglomerates, e.g., for fieldwork, it could be possible to overcome this issue.

In principle, interaction with humans will allow for the development of any kind of study usually performed in the field or in the laboratory. However, besides problems involving communications, there is a major issue regarding observations at several scales 
and azimuths. Human flexibility allows using other complementary tools, such as satellite imaging.

Remotely controlled electronic systems dispense the presence of humans at the study site (field or laboratory). In principle, this option could be implemented in ways compatible with total human confinement (excluding the need for human intervention for equipment maintenance). However, there is an issue surrounding the distance range for controlling the electronic devices (we expect that this will significantly improve in the future). These electronic systems could have several enhancements, such as different wavelengths (e.g., for scheelite observation). This sector might grow in the coming years as the necessary technology becomes more accessible.

The first step in performing fieldwork is to define the framework for the terrain survey, namely an initial recognition of the objects that will be studied, which might be modified according to the results of these preliminary data (e.g., further, more detailed studies, of constituents of these objects).

There are already several examples of the use of autonomous electronic systems in terrain studies. We can refer to the study by Kromer et al. [2], concerning the monitoring of mass movements in rock slopes, with a land station equipped with a time-lapse camera system. One can also find examples of the use of aerial vehicles in terrain studies related to slope stability [3-5].

One of the challenges for autonomous electronic systems will be to perform hand tests used for characterizing geological samples, such as those described in [6]. Perhaps it will be possible to use electronic systems that perform physical tests on-site on the studied rocks and soils. Similar considerations will apply to sample collections.

Regarding laboratory work, students could go to the laboratory at specific times to perform the requested studies; collaboration with institutions would help to overcome travelling issues. In practice, restrictions on the number of students allowed in the laboratory at the same time, and the need for an instructor to be present, could make this excessively costly.

For hand samples, besides the study of samples in institutional spaces, it would be, in principle, possible to send samples to the student residences; afterwards, teaching staff can interact with the students remotely.

However, some properties of minerals cannot be taught by procedures where the students are physically removed from the samples; for example, taste (the students will lose the "chance" of tasting sylvite) and smell.

Performing studies of hand samples solely by electronic systems seem to be a significant challenge, due to the potential difficulties in handling the samples, especially for some of the properties that are frequently used in the study of hand samples of minerals and rocks. This will be the case, namely, for those that involve the manipulation of the samples, such as surface hardness, or for organoleptic properties (taste, smell). While, in principle, it should be possible to simulate these data based on the senses through neurological stimulation of the pertinent regions of the brain, besides the technical difficulties, this will certainly raise serious ethical issues. Nonetheless, in principle, any of these properties could be replaced for some kind of instrumental test.

In the case of microscopic studies, it will be harder, but not impossible, at least in principle, to send the physical items to the students, especially petrographic microscopes, which are costly and delicate equipment. In practice, it will be exceedingly difficult to distribute them among the usual number of students. However, this option might be possible for some students under special circumstances (in a more inclusive perspective). Moreover, one can hope that, if there is a market for them, it will be possible to obtain cheaper, sturdier, and more portable microscopes. It will be useful to remember that the first petrographic microscopes were handmade and used solar light (so, this will be a way to promote the use of renewable solar energy and an, albeit small, contribution to decarbonization). There are already publications with instructions on how to make a petrographic microscope [7], albeit without the possibility of obtaining interference figures. 
While it will be challenging to prepare conditions for students to mount their petrographic microscopes, the long-term benefits could be enormous. Furthermore, the changes required to prepare sturdier, portable, solar light-based petrographic microscopes will be much less dramatic than the change from room-sized to pocket-sized computers (which happened in less than a century), or the change that the first two authors saw during their lifetimes, from "the" computer in "a" lab to computers in our pockets.

It will be even harder to send equipment to students, such as X-ray diffractometers, where safety issues are much direr (impossible at present, and it does not seem viable to promote "home-made X-ray diffractometers", namely for safety reasons).

For remotely-operated instruments, such as microscopes or X-ray diffractometers, there are questions concerning the implementation details. An example of a computercontrolled petrographic microscopy can be found in research conducted by Fueten [8].

When assessing the potential relevance of these remote procedures in teaching Earth Sciences, one should consider the eventual impact on future professional activities. Remote operations could contribute to exploration and monitoring studies in locations that are isolated or not easily accessible, under conditions that limit the movements of people in general, especially those with temporary or permanent restrictions.

The discussion presented here, about traditional geological studies, can be extended to surveys of objects located outside of planet Earth. The teaching perspective could contribute toward valuing space missions with the transmission of observation and analysis in real-time. Additionally, training and investment in the development of remote procedures for the study of geological bodies can contribute toward implementing exploration and exploitation operations of other astronomical bodies (in this case, by interaction with remotely controlled electronic systems, at least for the immediate future-see below). Relevance of the issues concerning other celestial bodies might be illustrated by the existence of proposals for the protection of the geological objects in them, as shown in the publication on exogeoconservation by [9], converging with general questions about possible terraforming operations. The possibility of Mars colonization in the (relatively) near future has been widely discussed by a leading private company in this field, see, e.g., [10]; this should be a significant incentive for the development of these techniques in Earth Science teaching.

The use of remote electronic systems is an area where it seems that some companies are ahead of academic teaching, see, e.g., [11,12]. This could prompt questions on whether universities are failing at one of their main purposes (to prepare students for the workplace).

\section{Final Considerations}

Remote teaching procedures seem viable at the present moment, with reasonable investments, and can be done in a relatively expedited manner when they are based on human interactions (there are diverse options, in terms of the locations of the students and teaching staff, according to the objects and techniques involved).

Besides the more technical details related to observation and communication, one should also consider potential ethical issues (especially in terms of privacy) for distance lectures, using spaces where other students are present.

There are several issues concerning the use of interactions with electronic systems, including the financial costs required by the use of such systems. However, one should consider the many benefits that could be derived from the use of these electronic systems, not only for working students but also in terms of inclusivity. Furthermore, this creates an opportunity for geological teams to collaborate with informatic ones, since it could also contribute to the development of electronic solutions, with the potential of being implemented in other situations. In a similar fashion to what has happened with other technological solutions (e.g., cars, computers, phones, and drones), one can expect that the development of opportunities for the use of these electronic systems will make them both better and less costly. 
While all of the procedures discussed here will potentiate the future professional relevance of the students, the use of remotely controlled electronic systems will be especially useful for remote and inaccessible locations and any situation where human access is restricted. This will also include potential operation in extraterrestrial locations.

Universities should seriously consider these remote teaching techniques, and look at groundbreaking examples from companies, in order to better prepare their students for future professional settings.

Author Contributions: All authors made written contributions to the present paper. All authors have read and agreed to the published version of the manuscript.

Funding: This specific work received no direct external funding albeit it benefited from research work funded by several institutions (see below in the acknowledgments).

Institutional Review Board Statement: Not applicable.

Informed Consent Statement: Not applicable.

Data Availability Statement: Data sharing not applicable.

Acknowledgments: We would like to thank first and foremost all the authors of the freeware used for the preparation of this paper (more details in Materials and Methods and in the references). The Lab2PT-Landscapes, Heritage and Territory laboratory - UIDB/04509/2020 is supported by the Portuguese FCT - "Fundação para a Ciência e a Tecnologia". The authors also gratefully acknowledge the support of the CERENA (funded by a strategic project of the FCT-UIDB/04028/2020) and the LAMPIST of the DECivil, Instituto Superior Técnico, University of Lisbon, Portugal. The University Institute of Geology of the University of A Coruña (Spain) receives support from the Xunta de Galicia from the program "Consolidación y estructuración de unidades de investigación competitivas: Grupos de potencial de crecimiento" (ED431B 2018/47) and Redes de investigación (R2017/008). The first author would like also to thank his former MSc student Ana Patrícia Matos and to Prof. C. Leal Gomes (also from the Lab2PT/DCT-ECUM) for conversations that were the seed for the reflections on teaching by remote operations (interactions with other human agents in distant locations).

Conflicts of Interest: The authors declare no conflict of interest. The founding sponsors had no role in the design of the study; in the collection, analyses, or interpretation of data; in the writing of the manuscript, and in the decision to publish the results.

\section{References}

1. Shew, A. Let COVID-19 expand awareness of disability tech. Nature 2020, 581, 9, doi:10.1038/d41586-020-01312-w.

2. Kromer, R.; Walton, G.; Gray, B.; Lato, M.; Group, R. Development and Optimization of an Automated Fixed-Location Time Lapse Photogrammetric Rock Slope Monitoring System. Remote Sens. 2019, 11, 1890, doi:10.3390/rs11161890.

3. Wang, S.; Zhang, Z.; Wang, C.; Zhu, C.; Ren, Y. Multistep rocky slope stability analysis based on unmanned aerial vehicle photogrammetry. Environ. Earth Sci. 2019, 78, 260, doi:10.1007/s12665-019-8145-z.

4. Al-Rawabdeh, A.; He, F.; Moussa, A.; El-Sheimy, N.; Habib, A. Using an Unmanned Aerial Vehicle-Based Digital Imaging System to Derive a 3D Point Cloud for Landslide Scarp Recognition. Remote Sens. 2016, 8, 95, doi:10.3390/rs8020095.

5. Tung, W.Y.; Nagendran, S.K.; Mohamad Ismail, M.A. 3D rock slope data acquisition by photogrammetry approach and extraction of geological planes using FACET plugin in CloudCompare. In IOP Conference Series: Earth and Environmental Science; IOP Publishing: Bristol, UK, 2018; Volume 169, p. 012051, doi:10.1088/1755-1315/169/1/012051.

6. Bamford, W.E.; Barton, C.M.; MacMahon, B.; Kanji, M.; Babcock, K.; Boyd, J. International society for rock mechanics commission on standardization of laboratory and field tests. Int. J. Rock Mech. Min. Sci. Geomech. Abstr. 1978, 15, 319-368, doi:10.1016/ 0148-9062(78)91472-9.

7. Elkins, L. Petrographic Microscope Home Kit for Smartphones. Available online: https://serc.carleton.edu/teachearth/activities/237997.html (accessed on 13 September 2020).

8. Fueten, F. A computer-controlled rotating polarizer stage for the petrographic microscope. Comput. Geosci. 1997, 23, 203-208, doi:10.1016/S0098-3004(97)85443-X.

9. Matthews, J.J.; McMahon, S. Exogeoconservation: Protecting geological heritage on celestial bodies. Acta Astronaut. 2018, 149, 55-60, doi:10.1016/j.actaastro.2018.05.034.

10. Available online: https://www.planetary.org/articles/20170929-spacex-updated-colonization-plans (accessed on 19 November 2020). 
11. Available online: https://spectrum.ieee.org/automaton/transportation/self-driving/robot-vehicles-make-contactless-deliveriesamid-coronavirus-quarantine accessed on 19 November 2020).

12. Available online: https://www.bbc.com/news/business-5443105 (accessed on 19 November 2020). 